\title{
An unusually late presentation of polycystic kidney disease with epilepsia partialis continua
}

\author{
Nanayakkara PGCJ ${ }^{1}$, Pathirana $\mathrm{KD}^{2}$, LAAAbeywickrema ${ }^{3}$ \\ ${ }^{1}$ Regisrar in Medicine, ${ }^{2}$ Consultant Neurologist, ${ }^{3}$ Senior Registrar in Medicine, University Medical Unit, \\ Teaching Hospital, Galle.
}

e-mail address of the corresponding author,Dr.P.G.C.J.Nanayakkara: chathu.nanayakkara@yahoo.com

\section{Introduction}

Epilepsia partialis continua (EPC) is a condition in which persistent focal motor clonic seizures occur at least for 60 minutes, but often for hours, days or even up to years ${ }^{1,2}$. EPC is a form of partial status epilepticus ${ }^{3}$, usually with preserved consciousness ${ }^{2}$. It can be associated with many factors ${ }^{4}$ such as cerebral neoplasia, cortical dysplasias, infections, vascular diseases, trauma, and metabolic causes. It may sometimes be idiopathic ${ }^{5}$. We report a 55 yearold patient who presented with persistent focal fits despite antiepileptic treatment due to uraemic encephalopathy caused by previously undiagnosed polycystic kidney disease.

\section{Case report}

A 55 year-old man with a history of hypertension for 8 years with poor follow up, had a brief febrile illness for 3 days, one week before admission. He was treated at the local hospital as for viral fever. Three days before admission, he developed abnormal movements of the right face and right upper limb which were persistent even during the sleep. The movements started on the right side of the face with twitching of right angle of mouth and quickly marched to the right arm and then to the right leg. The patient was conscious throughout the attack but could not speak properly due to continuous jerky movements of the face. There was no aura, other body movements, tonicity or faecal or urinary incontinence. He complained of feeling unwell and generalized body weakness. He had reduced urine output but there was no dysuria or other urinary symptoms. He was admitted to the local hospital where markedly elevated blood urea and serum creatinine were detected. He was then transferred to the Teaching Hospital Galle for haemodialysis.
In the past, he never had haematuria, frothy urine, symptoms suggestive of recurrent urinary tract infections, recurrent abdominal pains, strokes or fits. There was no family history of renal diseases, hypertension, fits, intracerebral haemorrhages or strokes. He was not on any regular medication but had taken antihypertensives on and off from a general practitioner. He had been a heavy social drinker but had stopped drinking alcohol few years ago. He was a non-smoker.

On examination, he was conscious and rational, had dysarthria due to facial jerks. There were stereotyped jerky movements of the right side of the face and right upper limb. There was no weakness or sensory impairment in the limbs. Rest of the neurological examination including the optic fundi was normal. Cardiovascular and respiratory systems were clinically normal. Abdominal examination was clinically normal and kidneys were not ballotable.

Investigations were as follows: blood urea: 138 $176 \mathrm{mg} / \mathrm{dL}$, serum creatinine $6.8 \mathrm{mg} / \mathrm{dL}$, serum sodium $124-128 \mathrm{mmol} / \mathrm{dL}$ with potassium $4.7-4.8$ $\mathrm{mmol} / \mathrm{dL}, \mathrm{Hb}-10.5 \mathrm{~g} / \mathrm{dL}, \mathrm{WBC}-8000 / \mathrm{mm}^{3}, \mathrm{~N}-$ $61 \%$, platelet count $115,000 / \mathrm{mm}^{3}$. Blood picture was compatible with anaemia of chronic disorder. Serum calcium was $6.50 \mathrm{mg} / \mathrm{dL}$ and magnesium was 2.10 $\mathrm{mg} / \mathrm{dL}$. Ultrasound scan of the abdomen showed multiple cysts in both kidneys with increased cortical echogenicity indicating polycystic kidney disease with chronic renal failure. Ultrasonically, other organs did not contain cysts. EEG was grossly abnormal with generalized increase in theta and delta waves without epileptiform discharges, and these findings were compatible with uraemic encephalopathy. CT scan of the brain was normal.

The diagnosis of epilepsia partialis continua due to uraemia caused by autosomal dominant polycystic kidney disease was made. He underwent few cycles 
of haemodialysis and was started on phenytoin sodium. In four days' time the jerky movements improved with improvement of uraemia.

\section{Discussion}

Adult polycystic kidney disease patients can present with different presentations, including fits in uraemic patients. But, in this patient, the "fits" or the jerky movements of the face was partial and lasted for a week without losing consciousness.

EPC was first described by Kozhevnikov in $1895^{1,5}$. In EPC, focal motor clonic seizures occur without loss of consciousness as mentioned earlier ${ }^{1}$. It may last for hours or days and rarely even for years ${ }^{1,2}$. In our patient it continued for one week. Any muscle group can be involved with face, distal limb and trunk getting affected more commonly ${ }^{1,4,6}$. The origin is cortical in majority of the cases ${ }^{1,4,6,7}$ and in some it is in subcortical structures ${ }^{1}$ like brain stem and basal ganglia. Some may be accompanied by Jacksonian spread into complex partial or secondary generalized seizures $^{3}$.

EPC can be caused by a variety of pathologies. (Table 1)

\section{Table 1 - Causes of Epilepsia partialis continua ${ }^{4}$.}

\begin{tabular}{|l|}
\hline Cerebrovascular diseases - \\
- $\quad$ Embolic or thrombotic ischaemic stroke \\
- $\quad$ Cerebral venous thrombosis \\
- A-V malformotions \\
Cerebral tumours - \\
- $\quad$ Metastatic tumours \\
- $\quad$ Gliomas \\
Metabolic - \\
- Diabetic ketoacidosis \\
- Non- ketotic hyperglycaemia \\
- Hepatic or Uraemic encephalopathy \\
Infections - \\
- Encephalitis \\
- Infective granuloma \\
- Cerebral abscesses
\end{tabular}

In addition to the above, children may present following Rasmussen encephalitis, cortical dysplasias, and genetic disorders (e.g. mitochondrial cytopathies-MELAS, Alper's disease $)^{4}$.

The EEG abnormalities include focal or diffuse slow waves of theta and delta range which are nonspecific. A MRI scan is needed if structural pathology is suspected. Special investigations such as PET scan and SPECT scan are used to evaluate metabolic effect of the disease, especially when CT or MRI scans are normal ${ }^{8,9}$.

Prognosis depends on the underlying cause ${ }^{2,5}$. It has been shown that anti-epileptic drugs are unsuccessful in altering the course or outcome of the disease ${ }^{10}$. Neurosurgical intervention has been tried in few cases ${ }^{6 .}$

Focal seizures in our patient improved following haemodialysis with the improvement of uraemia. Uraemia need to be considered in differential diagnosis of EPC and underlying causes including polycystic kidney disease need to be excluded in all such cases. In our patient hypocalcaemia may also have been contributory.

This case is unusual as EPC was the first manifestation of adult polycystic kidney disease. After extensive literature search, we were unable to find a case of polycystic kidney disease presenting with EPC as its first manifestation.

\section{References}

1. Carlos Maurício de Castro - Costa, Otonic C. Do Vale, Vicente Leitão, Carlos A. C. Teixeira, José Arnaldo M. de Arruda, Veralice S. de Bruin, Wagner G. Horta, Francisco M. B. Da Cunha, José Arthur C. D'almeida, Maria Risolene, Bitu Alencar. Epilepsia Partialis Continua (Koshenvnikov) - A preliminary case report; Arq. Neuro-Psiquiatr vol.58 n. 3B Sคo Paulo Sept. 2000. PMID: 11018833.

2. FB Scholtes, WO Renier, and H Meinardi. Simple partial status epilepticus: causes, treatment, and outcome in 47 patients; Journal of Neurology, Neurosurgery and Psychiatry 1996 July; 61(1): 90-92. PMID: 8676168.

3. Dominik Zumsteg and Richard A. Wennberg. A 61-yearold man with continuous clonic jerks of his right leg. CMAJ 2005 September 27; 173(7): 754-5. PMID: 1618658. 
4. Kumar S. Epilepsia partialis continua stopped by insulin. $J$ R Soc Med 2004 Jul; 97(7): 332-3. PMID: 15229261.

5. Bien CG, Elger CE. Epilepsia partialis continua. Semiology and differential diagnoses 2008 Mar; 10(1): 3-7. PMID: 18367424.

6. Nayak D, Abraham M, Kesavadas C, Radhakrishnan K. Lingual epilepsia partialis continua in Rasmusen's encephalitis. Epileptic disorders 2006 June; 8(2): 114-7.

7. Albernto J Espay, Vincent J Schmithorst and Jerous P Szaflarski. Chronic isolated hemifacial spasms as a manifestation of Epilepsia partialis continua. Epilepsy behaviour 2008 Feb; 12(2): 332-6. PMID: 17951112.
8. Buchpigned CA, Cukiert A, Hironaka FH, Ceri GG, Magalhues AE, Marino Júnior R. Brain SPECT in the pre-surgical evaluation of epileptic patients. Arq Neuropsiquiatr, 1992 Mar; 50(1): 337-42. PMID: 1307477.

9. Katz A, Bose A, Lind SJ, Spencer SS. SPECT in patients with epilepsia partialis continua. Neurology, 1992 May; 42(5): 1127-8. PMID: 2123308.

10. C Scherer. Seizures and non-ketotic hyperglycaemia. Neurology La Presse Médicale, 2005 Sep; 34(15): 1084-6. 